\title{
Evidentiality in gendered styles in spoken English
}

\author{
Erika Berglind Söderqvist, Uppsala University
}

\section{Introduction}

\subsection{Aim and scope}

Previous research (e.g. Holmes and Stubbe 2003; Ladegaard 2011) has identified and studied a number of linguistic features and characteristics that, when combined in a speaker's utterance, are generally perceived as a 'feminine' or a 'masculine' style. Using spoken language data from the British National Corpus (BNC), the present study seeks to answer the questions of whether the use of evidential markers varies across these 'gendered' styles, regardless of the gender of the speaker, and whether any variation found reflects the previously found differences in 'evidentiality' use between female and male speakers (Berglind Söderqvist 2017a; 2017b). In what follows, I will outline what is meant by evidentiality and 'evidential markers' in the present study.

Evidentiality is "the linguistic expression of the kind, source and/or evaluation of the evidence for or against the truth of the proposition that the sp[eaker]/ wr[iter] has at his/her disposal" (Carretero and Zamorano-Mansilla 2013: 17). In English, which is the focus of the present study, evidentiality refers to a linguistic category based on function rather than form; it is marked by means of lexical forms whose evidential function is often determined by the context. Examples (1) through (3) ${ }^{1}$ illustrate the three commonly used main categories (e.g. Willett 1988) of evidentiality:

(1) The one that's Down In The Borders yes, I mean that, I've seen so-- , another piece of print about that one Down In The Borders and erm $<$ pause > it's, it's not our version of audio description [...] (F7C 1096)

(2) Now hopefully, Dick said they're palletizing while they're waiting for the containers they're also palletizing the rest of that stuff. (JTB 985)

(3) I imagine they would both want to come back anyway. (JA9 414) 
Example (1) shows sensory evidentiality. The speaker first responds to some preceding utterance, says "I mean that" to signal that s/he is going to explain her response, and then communicates that s/he knows Down In The Borders does not feature a certain version of audio description because s/he perceived it firsthand, using one of her/his physical senses: eyesight. Example (2) represents hearsay evidentiality, where a speaker signals that $\mathrm{s}$ /he knows of something from someone else's report. Example (3), finally, shows inferential evidentiality, which signals that the information the speaker refers to was acquired using a cognitive process of inference, based on knowledge of the topic that may or may not be explicated.

In the three examples above, the underlined words are what will be referred to in this study as evidentiality markers. In the case of sensory and hearsay evidentiality, the sense of the marker is usually related to the act of using one's physical senses for evidence acquisition, or the act of producing or receiving a report. In expressions of inferential evidentiality, the sense of the marker tends to relate either to the cognitive process used for the inference, which is the case with imagine, or implicitly to the existence of the evidence that the inference is based on (e.g. obviously, clearly, seem, appear). What all markers have in common, according to the view of evidentiality adhered to for the purpose of this study, is that they allude to the acquisition or existence of evidence for or against the content of a proposition. Depending on the evidential marker and how it is used, it may or may not overlap with epistemic modality, meaning the expression of the speaker's assessment of how certain something is. Departing from the definition and scope of evidentiality described here, the present study will explore the functions carried out and effects achieved in interaction by means of marking evidentiality. By comparing the use of evidentials by speakers of feminine and masculine styles, respectively, I aim to investigate whether there are patterns to suggest that evidentials are used to different effects depending on whether they occur in stretches of speech that correspond to a feminine or a masculine style. In order to place focus firmly on the speech identified as feminine or masculine (as opposed to on the gender of the person who produces it), speaker gender will not be considered during the analysis. Any findings based on the primary data of this study will then be related to the previous findings that show quantitative differences in evidentiality use between women and men, to explore whether and to what extent variation across gendered styles and variation between female and male speakers in terms of evidential marking reflect one another. If they do, knowledge of the use of evidentials in gendered styles might contribute to an explanation of why women have been found to use evidentials more frequently (Berglind Söderqvist 2017b). 
Aiming to investigate whether there is a co-variation of evidentiality functions with gendered communication styles, and a possible relationship of such a co-variation with the previously-found quantitative differences between women's and men's use of evidentiality, the present paper is structured as follows. In order to clarify the background and motivations of this study, three areas of previous findings will be discussed and related to the aim and scope of the present paper, namely, i) the functions of evidentiality in interaction, ii) gender variation in evidentiality and other areas of language, and iii) the characteristics and significance of gendered styles. Thereafter the research questions will be specified (Section 1.2). Moving on to the methodology adopted for the present study, the sampling of data from the British National Corpus will be described (Section 2.1), as well as the method of operationalizing gendered styles (Section 2.2), and how coding and the qualitative analysis of evidentiality functions were carried out (Section 2.3). Next, the findings of the analysis will be presented: the identification of gendered styles as well as the functions of evidentiality markers in the language of speakers using different styles (Section 3). Finally, the findings will be discussed, and the conclusions will be presented along with some suggestions for further research (Section 4).

\subsection{Background: Evidentiality in interaction and gender-based variation in communicational styles}

In order to establish the background for the present study, this section covers three areas: first, an overview will be given of the pragmatic functions evidential markers have been found to be part of; second, the ways in which gender has been studied as interacting with language use in general, and evidentiality in particular, will be reviewed; and third, gendered styles, the way they have previously been defined and studied, and the approach taken in the present study will be described. The interrelatedness of these three areas will be explained, as well as their relevance to the aim of the present study, and then finally, the research questions of this study will be presented.

I will turn, first, to the functions performed by means of evidential marking. As touched upon in Section 1.1, functions here refer to what evidentiality is used for in interaction. For example, it has been found that evidentials (among related expressions of knowledge) are used as speakers negotiate their own knowledge status as relative to that of their addressees; it is a means of reaching consensus on the knowledge of all interlocutors about the topic of conversation (Drew 2018). It has also been argued that evidentials can have the effect of facilitating information-processing for the addressee by providing the speaker's evaluation of the reliability of that information (Cappelli 2007), and that marking evidenti- 
ality indicates that the speaker distances her-/himself from authority, responsibility, and/or entitlement regarding the topic (Fox 2001). Finally, Berglind Söderqvist (forthcoming) found that when used in casual conversation, evidential markers are frequently instrumental in relational practice (e.g. Holmes and Marra 2004), for example by means of face maintenance strategies. In summary, the pragmatic potential of evidential marking clearly extends beyond providing information about evidence.

The second aspect to be considered in the present section concerns previous findings regarding gender-based variation in communicational behavior. Newman et al. (2008) conducted a meta-study, analyzing data that comprise a corpus of 45,700,000 words from various linguistic genres (93 percent written and 7 percent spoken) in English. They used the text analysis program Linguistic Inquiry and Word Count (LIWC), capable of recognizing about 80 percent of the words of a text and categorizing them according to functional as well as semantic properties, to test for quantitative linguistic differences between the speech of men and women. Setting the significance limit at $p<.001$ because of the large sample size, Newman et al. found that women's language is more likely to contain verbs, pronouns, and references to social and psychological processes (words like friend, talk, nervous, feel) and to the home (words like house, kitchen, lawn). They find men more likely to produce numbers, prepositions, and words of over six letters, as well as references to objects and external processes such as occupation, money, and sports. It has also been found, using conversation data, that women are more likely to produce supportive utterances (Holmes and Stubbe 1997) and to be more engaged in performing and managing relational practice than men are (Merrill et al. 2015).

As for gender-related ${ }^{2}$ evidentiality preferences, in addition to finding that women use evidentiality markers more frequently overall, Berglind Söderqvist (2017a) found women to prefer inferential evidentials that tend to denote evidence that is available only to the speaker (such as think, suppose, imagine), whereas men were found more likely to use markers that often denote evidence that is (potentially) available to the addressee as well as the speaker (such as seem, appear, obviously, clearly). Further, Berglind Söderqvist (2017b) found women's higher likelihood to mark evidentiality to be the most pronounced for hearsay evidentiality markers. It is possible to draw parallels between these findings and the findings of Newman et al. (2008) that women are more likely to talk about the emotions, thoughts, and experiences of people as well as use personal pronouns. It is highly likely that expressing an assessment of one's evidence acquisition as being potentially subjective, or referencing reports of others would co-occur with $3^{\text {rd }}$ person pronouns and mentions of people's experiences. 
Also possibly related to the findings on gender-related preferences, Cornillie (2009: 58) argued that evidential expressions denoting shared evidence will be perceived as more reliable than an evidential basis accessible for the speaker only. Fox (2001) demonstrated that not marking evidentiality in a context where it could have been marked expresses greater authority on the part of the speaker as compared to overtly marking evidentiality, suggesting a relationship between evidentiality use (or the lack of it) and communicational style. To put it briefly, women's language appears to orient more strongly toward social aspects, regarding content as well as interactional behavior, whereas men's language seems more likely to be direct and referentially oriented. The nature of these differences found between men's and women's typical linguistic behavior resembles the differences between a feminine and a masculine style, which will be discussed next.

The third area of previous research related to the topic of the present paper to be discussed, then, is the one in focus of the present study: the concept of gendered styles. Holmes and Stubbe (2003) present a list, here reproduced in Table 1 , of what they find to be commonly cited features of feminine and masculine styles of communication:

Table 1: Features of interactional styles (adapted from Holmes and Stubbe 2003: 574)

\begin{tabular}{ll}
\hline Feminine & Masculine \\
\hline Indirect & Direct \\
Conciliatory & Confrontational \\
Facilitative & Competitive \\
Collaborative & Autonomous \\
Minor contribution (in public) & Dominates (public) talking time \\
Supportive feedback & Aggressive interruptions \\
Person/process-oriented & Task/outcome-oriented \\
Affectively oriented & Referentially oriented \\
\hline
\end{tabular}

The features listed in Table 1, or variants of them, have since been successfully applied in investigating the use and effect of gendered communication styles (e.g. Ladegaard 2011; McDowell 2015). The difference between gender variation in language use and gendered communication styles is that the latter con- 
cerns the performance of femininity and/or masculinity, regardless of the actual gender of the speaker. As Holmes (2008: 480) notes, speakers of both genders employ features from both ends of this stylistic scale as appropriate to the situation and the speaker's role in that particular situation; for example, it has been found that the communicational and behavioral norms of a community of practice determine the acceptability of a gendered style from either side of the feminine-masculine scale (Holmes and Schnurr 2006; Ladegaard 2011).

While one should be wary of presuming a one-to-one correspondence between gender and gendered styles, the findings of gender variation in language use cited previously in the present section reflect some of the features listed in Table 1. For instance, it seems to be the case that a typically female use of evidentiality (frequent evidentiality markers, particularly hearsay; tendency to prefer inferential evidentials denoting non-shared evidence) indicates a communication style that orients toward the thoughts and experiences of self and others, and toward striving for informational transparency and consensus, which fits with features such as affective, collaborative, and supportive in the feminine column of Table 1. A typically male use of evidentiality, on the other hand (less frequent use of evidential markers, tendency to prefer inferential evidentials denoting shared evidence), indicates assertiveness, a more direct kind of authority, and less of a focus on informational transparency and consensus, which calls to mind the features autonomous, direct, and referentially oriented from the masculine column of Table 1 .

The present study targets this suggestion that use of evidential markers might be influenced by the kind of style a speaker uses, and aims to test whether evidentials are used to different effects and functions depending on the style used by the speaker in whose utterance the evidential marker is found. In order to operationalize gendered styles, linguistic features likely to indicate the characteristics listed in Table 1 will be identified and used during the analysis (see 2.2). The research questions that will be answered in order to materialize the aims described here are: (1) Is evidential marking used for different functions depending on whether the communicational style is characterized by feminine or masculine behaviour, and (2) If evidentiality functions are found to co-vary with variation in gendered styles, are there indications that the differences in evidentiality use between a feminine and a masculine style mirror the differences found in evidentiality use between women and men? 


\section{$2 \quad$ Material and method}

\subsection{Corpus and sampling}

The material for this study was extracted from the meeting category of the spoken-language section of the British National Corpus (BNC). The meeting category comprises conversations where people meet for previously-agreed upon purposes, most of them recorded in the early 1990s. Meetings were selected because they tend to feature some spontaneity, which is likely to be revealing of personal styles; yet because of the commonly occurring setting where people sit still around a table, the recordings (and the transcripts) are generally of a good quality. Additionally, the category ensures some degree of homogeneity (and comparability) across texts.

Since there are indications that features of gendered styles correlate with the gender of speakers (see Section 1.2), the sample was balanced for gender. In the BNC Corpus Query Processor (CQP) interface, a search was conducted for all speakers in the meeting category tagged as being female and native speakers of British English, which yielded 98 speakers. In cases where there were several speakers from the same text file, only the speaker with the highest word count from that text file was selected; this procedure yielded 36 female speakers. When a corresponding search was conducted for male speakers, 268 speakers were returned. I performed the same procedure as with the female speakers, selecting the speaker with the highest word count from each text file, until 36 male speakers were accumulated.

Ultimately, the material of this study consists of 72 speakers, distributed across 48 text files. These 48 text files comprise 578,198 words, but the speakers used as informants produce 201,764 words, as shown in Table 2:

Table 2: Speakers in the material and their word counts

\begin{tabular}{|l|l|l|}
\hline & Speakers & Words \\
\hline Female & 36 & 79,200 \\
\hline Male & 36 & 122,564 \\
\hline Total & 72 & 201,764 \\
\hline
\end{tabular}

As seen in Table 2, there is a considerable difference in word counts between the female and the male speakers. However, this imbalance is of little relevance to the present study, which presents an investigation of gendered styles rather than the influence of gender on a speaker's production. The communication style of each speaker is analyzed without consideration of the gender of that speaker; hence, harmonizing the word counts of the gender groups was not deemed necessary. 


\subsection{Operationalizing gendered styles}

To be able to compare functions of evidential marking across variation in communicational behaviour and style, the 72 speakers were ranked according to the extent to which they communicate in a stereotypically feminine or masculine way. Out of the list presented in Table (1) (Section 1.2), three dimensions were selected as the focus of the operationalization of the feminine-masculine style continuum for the purpose of this study: conciliatory/confrontational, collaborative/autonomous, and affectively oriented/referentially oriented. Each of these three stylistic dimensions was then operationalized in the form of indicators, which are explained and defined in the following sections. The indicators were coded for in the material and form the basis for ranking speakers according to stylistic behavior.

\subsubsection{Conciliatory/confrontational}

This dimension is primarily concerned with the apparent attitude of the speaker concerning conflicts and face threats. The conciliatory/feminine side of this dimension is operationalized by coding for justifiers, which Mulac et al. (1988) find to be used more often by women. Mulac et al. define them as "[e]vidence or reason given for a statement" (1988: 322). To avoid overlap with evidentiality, the evidence aspect was excluded from the definition of justifiers for the purpose of this study; I define justifiers as providing an explanation or justification for a previously made statement. A typical occurrence of this stylistic indicator can be seen in Example (4) from text file KM8:

Example (4). Justifier.

$\begin{array}{lll}\text { PS6SY } & 510 & \begin{array}{l}\text { I was walking that way with Ernest <gap } \\ \text { desc="name" reason="anonymization"> on Saturday } \\ \text { and he said he thought the bottom hedge belonged to } \\ <\text { gap desc="name" reason="anonymization"> any- } \\ \text { way. } \\ \text { Well I don't think that's right }\end{array} \\ \text { PS6SW } & 511 & \begin{array}{l}\text { No. } \\ \text { KM8PSUNK } 512\end{array} \\ \text { PS6SW } & 513 & \begin{array}{l}\text { I I don't I don't think that's right Glynis because } \\ \text { That's okay then. } \\ \text { PS6SY }\end{array} \\ 514 & 515 & \begin{array}{l}\text { I just thought I'd mention it because I didn't want any- } \\ \text { body }\end{array}\end{array}$


After line 515 of Example (4), speaker PS6SY is interrupted; but what $\mathrm{s} / \mathrm{he}$ is attempting to do in the underlined utterance is to provide an explicit reason or justification for the utterance in line 510, after being contradicted by speaker PS6SW.

The confrontational/masculine end of this stylistic dimension is operationalized as the indicators challenge and confrontation. A challenge is defined as directly or indirectly challenging or contradicting the content of another interlocutor's utterance; Holmes and Stubbe (1997) find men more likely to produce challenging responses. Confrontation has to do with behavior rather than a challenge of propositional content; it is here defined as showing overt disregard for the face wants of other interaction participants, for example by explicitly accusing someone of doing something generally unaccepted.

\subsubsection{Collaborative/autonomous}

The dimension collaborative/autonomous concerns the way speakers relate to other interlocutors. The collaborative/feminine pole of this continuum is realized in the form of indicators question, $2^{\text {nd }}$ person personal pronouns, extended feedback, and positive feedback. Utterances that are coded as questions usually have interrogative syntax, but not always; the defining feature is that the behavior of interlocutors indicates that the utterance is intended and understood as a question, i.e. that an answer is expected. Rhetorical questions are not included, nor tag questions. $2^{\text {nd }}$ person personal pronouns include all second-person personal pronouns; these have been found to be produced more often by women (Newman et al. 2008).

Feedback is defined as a verbal reaction to another interlocutor's utterance that does not add new information (aside from the speaker's attitude or opinion). Holmes and Stubbe (1997) find the type of feedback speakers use to be indicative of their relative supportiveness during a conversation; they found men more likely to produce challenging responses and minimal feedback, and women more likely to produce extended and overtly positive feedback. The latter two types are included in this dimension. Extended feedback is feedback that is affectively and semantically richer than minimal responses such as hmm, $O K$, yeah; examples of extended feedback include expressing agreement, echoing the other interlocutor's words, or making a brief comment. Positive feedback is explicitly positive, such as saying good idea or that's excellent. Examples (5) and (6), from text files G5K and JP0, respectively, illustrate feedback during interaction: 
Example (5). Extended feedback.

$\begin{array}{lll}\text { PS2BB } & 501 & \\ & 502 & \text { Your home can be }<-\mid->\text { your idol. } \\ & \text { Everything can }<\text { unclear }><-\mid-> \\ \text { PS2B5 } & 503 & <-\mid->\text { Oh very much so. } \\ & 504 & <-\mid->\text { Yeah. } \\ & 505 & \text { Yeah. }\end{array}$

Example (6). Positive feedback.

PS4GR 993 All of them have come out of the time over the nineteen ninety three have all been employed by the company.

PS4GM $994 \quad$ Ah that's terrific.

PS4GR 995 Erm so yes I think we're we can we can < unclear> say we've been leading from the front.

PS4GM $996 \quad$ Yeah good.

In Example (5), which is taken from a recording of a Bible discussion group, a participant suggests that one can view one's home as an idol (501). Speaker PS2B5, who is the discussion moderator, expresses strong support for this suggestion by her/his extended feedback (503-505). In Example (6), speaker PS4GM explicitly and repeatedly expresses her/his positive attitude $(994,996)$ toward what PS4GR is reporting.

The autonomous/masculine end is operationalized as the indicators directive and interruption. Directive is defined as telling another interlocutor how to act, and doing so in a direct manner; that is, without hedges. Newman et al. (2008) find men more likely than women to produce directives. Interruption is defined as starting a new turn before another interlocutor finishes his/hers, with the exception of cooperative overlaps (Holmes and Stubbe 1997), which function as feedback rather than interruptions. Mulac et al. (1988) find men to interrupt more often than women.

\subsubsection{Affectively oriented/referentially oriented}

The dimension discussed in the present section concerns the extent to which the language of the speaker reveals the speaker's feelings or makes relevant the feelings or experiences of other people, as opposed to simply transferring information. As previously mentioned, the transcribed meetings comprising the material of this study consist of the speech of people meeting for previously agreed-upon purposes; generally, those purposes have something to do with 
problems needing to be solved. This aspect of the texts tends to promote references to tasks, outcomes, external processes, and numbers; all such features are associated with a masculine style. The nature of the material also promotes a referential orientation; information (rather than feelings) is generally the explicit focus of the meetings. For this reason, the affective/referential dimension is operationalized in the form of the presence or absence of indicators of an affective/feminine orientation, namely people reference, intensive adverbs, and affect reference. These indicators (or a close approximation in the case of people reference; see discussion in the following paragraph) were found by Newman et al. (2008) to be produced by women more often than men.

People reference is defined as referring to the experiences, thoughts, and/or emotions of other people beyond what is required by the purpose of the meeting. It corresponds roughly to Newman et al.'s (2008: 219) 'linguistic dimension' of social processes, which encompasses words denoting communication, friendship, family, and humans. Since the scope of this study enables the analysis of function beyond form, the definition of people reference was accommodated to the nature of the material. Some meetings revolve around a topic concerning people; examples include teacher conferences or political meetings on affordable housing. In order to avoid meeting-subject bias, only occurrences of people reference beyond what should be required by the topic of a meeting were counted. Mentioning the number of people facing homelessness because of lack of affordable housing would not be counted, for example, whereas speculation regarding the emotions a mother might experience as she faces homelessness would be counted as people reference. This kind of situation is shown in Example (7), from text file J8B:

Example (7). People reference.

\begin{tabular}{|c|c|c|}
\hline PS3S6 & 1428 & $\begin{array}{l}\text { That's a shame you know, because that's the ideal isn't it, } \\
\text { remember those wee titchy }<-\mid->\text { things at four }<-\mid->\end{array}$ \\
\hline PS3S4 & 1429 & $<-\mid->$ That's right $<-\mid->$ \\
\hline \multirow[t]{3}{*}{ PS3S6 } & 1430 & all my staff were crying which didn't help $<$ laugh $>$ \\
\hline & 1431 & $\begin{array}{l}\text { had to keep dragging them off to the toilet, they'd never seen } \\
\text { blind children you see they'd all seen adults }\end{array}$ \\
\hline & 1432 & $\begin{array}{l}\text { it's fine to be blind to be an adult, but these wee titchy things } \\
\text { and there's a little boy saying, you know I was really looking } \\
\text { forward to this, this is really exciting, totally blind ooh }\end{array}$ \\
\hline
\end{tabular}


Example (7) is taken from a meeting on audio description for blind people; in other words, talking about people and their needs is part of the purpose of the meeting. Here, however, speaker PS3S6 manifests an affectively oriented style by talking about people beyond what is required by the meeting topic; s/he describes how staff were brought to tears by meeting blind children, and how the children being "wee titchy things" made it more touching that they are blind than if they had been adults (1430-1432).

Intensive adverbs are all adverbs that upscale the intensity of the verb or adjective they modify, and affect reference is defined as explicit references to affect using words such as happy, sad, worry, love, hate, angry, and their derivatives.

\subsection{Coding and analysis}

Before the data were transferred to spreadsheets, speaker names were replaced by BNC speaker IDs. These were used in the hope of relieving the analysis of some of the bias that might be caused by studying the speech of a person explicitly and repeatedly identified as Graham or Cathy. As some of the speakers refer to each other by their first name, this procedure did not completely succeed in masking genders, but this approach was taken as an attempt to place as much focus as possible on actual speaking styles. For this reason, I was unaware of the gender of most speakers while conducting the analyses. The 48 text files were manually analyzed; while the utterances of other speakers were relevant to interpretations, only the utterances of the 72 informants were subject to coding.

The coding and analysis were conducted as follows. First, each text file was categorized into one of three categories, depending on the nature of the meeting. There are agenda-driven meetings and solution-driven meetings. Meetings of the former category tend to be committee or council meetings where there is explicit reference to an agenda and a chairperson. The meetings of the latter category are generally business-related; while there may be someone who leads or dominates the meeting, there are no explicit references to a written agenda or chairperson. During solution-driven meetings, as there is no chairperson to direct turn-taking, overlapping speech, humorous interactions, and digressions tend to be recurrent. The agenda-driven meetings are further divided into two categories: highly structured and semi-structured. During highly structured meetings, participants only speak when directed to by the chairperson, and the agenda is strictly adhered to. Semi-structured meetings tend to begin formally by the reading of minutes but proceed with participants appearing to speak up on their own accord. 
While the categorization of solution-driven vs. agenda-driven meetings was relatively straight-forward (is there or is there not explicit reference to an agenda or chairperson?), the basis for the classification of highly structured vs. semistructured meetings was somewhat more subjective. The main reason for categorizing the material according to meeting type is that it was noted during the initial stages of analysis that the nature of the meetings affected the use and frequency of several of the indicators targeted, such as feedback and interruptions. Further, it has been found that stance marking (which overlaps with some stylistic indicators targeted in this study) may vary with situational context (Biber 2006). Thus, the goal of classifying agenda-driven meetings as highly structured or semi-structured was to identify the more formal meetings where turn-taking was supervised to the extent of suppressing some interactional features that would occur more frequently with spontaneous turn-taking. While the nature of that distinction presented me with a few slightly ambiguous cases, it was generally possible to determine whether spontaneous turn-taking during the discussion of agenda items was sanctioned (semi-structured) or discouraged (highly structured).

Second, all markers of evidentiality were highlighted. The brief description in Section 1 of the evidentiality scope adopted for the present study was used as the starting point; for a more extensive description of criteria used to code for evidentiality, see Berglind Söderqvist (2017b). Unlike Berglind Söderqvist (2017b), however, the present study does not make use of a pre-defined list of search terms; instead, any and all evidentiality markers were coded for in the material. Simultaneously to coding for the stylistic indicators described in Section 2.2, brief comments were noted down about aspects that could influence the interpretation of indicator frequencies. Such comments include whether an informant is a chairperson, the salesperson or the prospective buyer of a sales meeting, or if an informant mainly speaks in the form of monologue.

Once the transcribed speech of the 72 informants had been coded for evidential markers and stylistic indicators, the raw frequencies of evidentials and indicators were normalized per 1,000 words, to allow comparison across speakers despite their varying word counts. The frequencies of individual indicators were combined into the stylistic dimensions they represent; for example, the normalized frequencies for challenge and confrontation were combined, resulting in a frequency for the dimension confrontational, for each informant.

Prior to ranking the informants, they were divided into three groups according to meeting type. The group of informants from solution-driven meetings has 34 speakers, the group from semi-structured agenda-driven meetings has 14 speakers, and the group from highly structured agenda-driven meetings has 24 
speakers. Within each of the three groups, speakers were rank-ordered in terms of having the most feminine to the most masculine style using the normalized frequencies of the stylistic dimensions conciliatory/confrontational, collaborative/autonomous, and affectively oriented/referentially oriented. The main guiding principle of the ranking process is that high frequencies of the feminine side of the dimensions (conciliatory, collaborative, and affectively oriented) and low frequencies of the masculine side of the dimensions (autonomous, confrontational) means that the speaker is ranked as using a feminine style, and the reverse would mean that a speaker is ranked as using a masculine style. Naturally, when using spontaneous spoken language data, such ranking presents the researcher with opportunities for problem-solving; four types of such opportunities are described below to exemplify how they were dealt with.

First, there are cases where a speaker displays relatively high frequencies for one or more of the feminine as well as the masculine indicators. In such cases, having relatively high frequencies for both autonomous and confrontational is viewed as carrying more weight than having a relatively high frequency for collaborative but not for conciliatory and affective, for example. In other words, the ranking was also guided by how many of the feminine or masculine indicators a speaker has high frequencies for.

Second, there are cases where the indicators were particularly difficult to code. In order to keep the genders of the speakers separate from the analysis, audio files were not used, which occasionally had a limiting effect. For example, speaker PS3V9 produces a number of utterances that appear confrontational but that might in fact, judging by the way they are received, be humorously intended. Speaker PS4GF is another such case; on several occasions, it is difficult to be certain whether her/his contributions should be interpreted as interruptions or cooperative overlaps. For these speakers, the frequency of the indicator inflicted by ambiguity was treated with caution.

Third, normalizing frequencies per 1,000 words makes it necessary to also treat the frequencies of the few speakers with total word counts of less than 1,000 with caution. While such speakers were not removed from my dataset, I avoided placing them at the far ends of the stylistic scales. Fourth, the speakers with very low frequencies for all stylistic dimensions presented a problem. Such cases could be interpreted as simply being extremely referentially oriented and thus masculine, particularly when also having relatively high word counts; still, speakers with low frequencies for all indicators were viewed as less masculine than speakers with high frequencies for autonomous and confrontational. 


\subsubsection{Evidentiality analysis}

Due to time constraints, it was not possible to make a fine-grained analysis of the function and effects of all the 798 evidentiality markers found in the material of this study. Instead, nine speakers were selected as representative of certain points on the relevant stylistic scale, and their use of evidentiality was carefully analyzed. From each of the three meeting-type groups, three speakers were selected: the one found to use the most feminine style, the one found to use the most masculine style, and one from the middle.

The 110 evidential markers produced by these nine speakers (which excludes three cases that were too ambiguous for analysis) were analyzed with regard to a number of factors: the topic and nature of the dialogue that is the context of the marker, the role of the speaker, the function of the particular utterance that the evidential is part of, and the apparent effect of adding an evidential marker to that utterance.

\section{Findings}

The present section will account for the findings of this study. First, Section 3.1 is dedicated to illustrating the results of the stylistic ranking. The stylistic characteristics of the three speakers selected to represent a feminine style, the three speakers representing a masculine style, and the three speakers representing a position in between masculine and feminine are exemplified, described, and analyzed. Then, in Section 3.2, the results of the analysis of evidentiality use across stylistic variation are described, exemplified, and discussed.

\subsection{Gendered styles}

As described in Section 2.3, determining the degree to which each individual informant is using a masculine or a feminine style, as relative to the other informants in the same meeting type category, was not a straightforward task. Some informants were relatively easy to place at either far end of the scale, but most use features of both styles. There are also cases where an informant changes his/ her style following some shift in the circumstances; such a shift occurred, for example, when an external consultant left a business meeting halfway through, seemingly allowing the informant to adopt a more assertive style than $\mathrm{s} / \mathrm{he}$ used while the consultant was present. Thus, not unexpectedly, it appears more common for speakers to use a style that is partly feminine and partly masculine, or to alternate between the two, than to consistently use one or the other. In order to be able to compare evidentiality use across distinct stylistic variation on the continuum from conciliatory, collaborative, and affectively oriented to confronta- 
tional, autonomous, and referentially oriented, the 'extremes' identified during this ranking process are used to demonstrate and exemplify the stylistic variation that is targeted.

Table 3 shows the speakers that were selected for this purpose: the most feminine $(\mathrm{F})$, the most masculine (M), and one intermediate (I) speaker from each of the meeting type groups solution-driven (S), agenda-driven semi-structured (AS), and agenda-driven highly structured (AH). The normalized per 1,000 words (and raw) frequencies of the stylistic dimensions conciliatory (Conc), collaborative (Coll), affective (Aff), autonomous (Aut), and confrontational (Conf) are also shown for each speaker:

Table 3: Speakers representing gendered styles, with their normalized (and raw) frequencies of stylistic dimensions

\begin{tabular}{|c|c|c|c|c|c|c|c|c|}
\hline Speaker & Words & Meeting & Style & Conc & Coll & Aff & Aut & Conf \\
\hline PS6MC & 7,026 & AS & F & $\begin{array}{l}1.71 \\
(12)\end{array}$ & $\begin{array}{l}31.31 \\
(220)\end{array}$ & $\begin{array}{l}8.4 \\
(59)\end{array}$ & $\begin{array}{l}0.71 \\
(5)\end{array}$ & $\begin{array}{l}0.57 \\
(4)\end{array}$ \\
\hline PS3S6 & 3,490 & S & $\mathrm{F}$ & $\begin{array}{l}0.57 \\
(2)\end{array}$ & $\begin{array}{l}35.25 \\
(123)\end{array}$ & $\begin{array}{l}17.77 \\
(62)\end{array}$ & $\begin{array}{l}3.44 \\
(12)\end{array}$ & $\begin{array}{l}0.29 \\
(1)\end{array}$ \\
\hline PS4FF & 1,875 & $\mathrm{AH}$ & F & $\begin{array}{l}2.13 \\
(4)\end{array}$ & $\begin{array}{l}36.8 \\
(69)\end{array}$ & $\begin{array}{l}10.67 \\
(20)\end{array}$ & $\begin{array}{l}1.6 \\
(3)\end{array}$ & $\begin{array}{l}1.07 \\
(2)\end{array}$ \\
\hline PS4H4 & 5,858 & AS & I & $\begin{array}{l}0.85 \\
(5)\end{array}$ & $\begin{array}{l}12.29 \\
(72)\end{array}$ & $\begin{array}{l}7.85 \\
(46)\end{array}$ & $\begin{array}{l}0.17 \\
(1)\end{array}$ & $\begin{array}{l}1.19 \\
(7)\end{array}$ \\
\hline PS1LN & 1,245 & S & I & 0 & $\begin{array}{l}28.11 \\
(35)\end{array}$ & $\begin{array}{l}1.61 \\
(2)\end{array}$ & $\begin{array}{l}1.61 \\
(2)\end{array}$ & 0 \\
\hline PS44V & 1,649 & $\mathrm{AH}$ & I & 0 & $\begin{array}{l}3.03 \\
(5)\end{array}$ & $\begin{array}{l}4.85 \\
(8)\end{array}$ & 0 & 0 \\
\hline PS4VB & 1,007 & AS & $\mathrm{M}$ & 0 & $\begin{array}{l}30.78 \\
(31)\end{array}$ & $\begin{array}{l}1.98 \\
(2)\end{array}$ & $\begin{array}{l}2.98 \\
(3)\end{array}$ & $\begin{array}{l}7.94 \\
(8)\end{array}$ \\
\hline PS41A & 2,238 & S & M & $\begin{array}{l}0.45 \\
(1)\end{array}$ & $\begin{array}{l}14.75 \\
(33)\end{array}$ & $\begin{array}{l}0.89 \\
(2)\end{array}$ & $\begin{array}{l}6.7 \\
(15)\end{array}$ & $\begin{array}{l}2.24 \\
(5)\end{array}$ \\
\hline PS3UM & 1,441 & $\mathrm{AH}$ & M & 0 & $\begin{array}{l}27.75 \\
(40)\end{array}$ & $\begin{array}{l}2.08 \\
(3)\end{array}$ & $\begin{array}{l}3.47 \\
(5)\end{array}$ & $\begin{array}{l}6.26 \\
(9)\end{array}$ \\
\hline
\end{tabular}

Quantitatively, it is a characteristic of the speakers found to use a feminine style that they exhibit all three feminine dimensions (conciliatory, collaborative, and affective), and fairly high frequencies of particularly collaborative and affective patterns (conciliatory is infrequent overall). The feminine speakers also have relatively low frequencies of autonomous and confrontational patterns, particu- 
larly the latter. Conversely, the speakers using a masculine style have relatively high frequencies of autonomous and confrontational patterns, and relatively low frequencies of the other three dimensions, especially conciliatory and affective patterns. Since Table 3 displays the extremes, the differences between the three meeting types are not readily visible here; the overall results show, however, that speakers in highly structured meetings tend to have lower frequencies of all indicators. That pattern is likely a result of the fact that highly structured meetings often feature monologues, speech that appears prepared, as well as turn-taking that is controlled by a chairperson.

In order to give a better picture of the stylistic variation targeted in this study, examples from the material are here briefly analyzed and discussed. Illustrating a feminine interactional style, Example (8) is from text file KLS and features speaker PS6MC, who is the chairperson of a semi-structured agendadriven meeting:

Example (8). Feminine style in semi-structured agenda-driven meeting.

$\begin{array}{lll}\text { PS6MC } & 226 & \text { Thanks every so much all of you any rate. } \\ \text { PS6MK } & 227 & \text { Mm Amy would you be on the committee? } \\ \text { PS6MC } & 228 & \text { Yeah. } \\ 229 & \text { Lovely, thank you. } \\ 230 & \begin{array}{l}\text { Erm, oh the raffle coffee morning I'm sorry I couldn't } \\ \text { come, but I was laid low erm how did it go? }\end{array} \\ & 231 & \begin{array}{l}\text { I gather you had }<-\mid-><\text { unclear }><-\mid-> \\ \text { KLSPSUNK }\end{array} \\ 232 & \begin{array}{l}<-\mid-><\text { unclear }>\text { Wednesday }<-\mid->\text { it went very well } \\ \text { indeed, yes, I, we made forty four pounds, twenty } \\ \text { nine pence on the day and then Betty went to Saw- } \\ \text { bridgeworth with some cushion covers and managed } \\ \text { to sell them off for another five pounds }<-\mid->\text { so we } \\ \text { got }<\text { unclear }><-\mid->\end{array}\end{array}$

PS6MC $233<-\mid->$ Oh lovely $<-\mid->$.

Example (8) shows speaker PS6MC providing positive feedback $(229,233)$, using $2^{\text {nd }}$-person pronouns $(226,227,229,231)$, and asking questions $(227$, 230). Example (8) also illustrates this speaker's general tendency for being strongly oriented toward the relational aspects of her/his interactions, as 
opposed to focusing only on information. S/he frequently expresses gratitude toward the other meeting participants (as in lines 226 and 229), and line 230 shows one of several instances where this speaker apologizes to the other meeting participants for failing to participate in something. As previously noted by Holmes and Schnurr (2006) and Ladegaard (2011), the norms of the community of practice in which an interaction takes place is highly relevant to the nature of a person's verbal performance of gender. Throughout text file KLS, the meeting participants fairly consistently use language that displays concern for the other interlocutors' face wants and for human experience in general, even when discussing topics such as budgeting, suggesting that the strongly feminine style used by PS6MC is probably partly a response to the norms of that community of practice.

The speakers using a style that is somewhere in-between masculine and feminine tend to use features of both styles, as shown in Example (9). This excerpt comes from text file KLT, which is a solution-driven meeting, and features speaker PS1LN:

Example (9). Intermediate style in a solution-driven meeting.

$\begin{array}{ll}\text { PS1LM } 3 & \begin{array}{l}\text { I want us to use }<\text { pause }>\text { we ne-- ee erm }<\text { pause }><-\mid->\text { static } \\ \text { resources }<-\mid->\end{array}\end{array}$

PS1LN $4<-\mid->$ So it's more participative.

PS1LM 5 Well, less participative, more <pause $>$ us teaching, the tu-teaching style will be $<$ pause $>$ you know, here's a slide show.

PS1LN $6<-\mid->$ Mm.

PS1LM $7<-\mid->$ I think we'll <-|->

PS1LN $8<-\mid->$ Oh I see.

PS1LM <unclear $>$

PS1LN 9 Oh I $<-\mid->$ I meant $<-\mid->$

PS1LP $\quad<-\mid-><$ unclear $><-\mid->$

PS1LN 10 are you going out and about looking at, I mean $<-\mid->$

Example (9) shows speaker PS1LN interrupting in line 4, providing extended feedback in line 8 , and using a $2^{\text {nd }}$-person pronoun in line 10 . Throughout text file KLT, this speaker tends to respond to other interlocutors rather than leading the conversation, which might suggest a feminine style, considering the results visible in Table 1 . Her/his responses, however, are generally minimal (as in line 6), making it difficult to interpret the level of supportiveness of this speaker 
without having access to information about prosody. As Holmes and Stubbe (1997: 11) note, the supportiveness of a semantically minimal response is shown by its prosody.

The speakers using a masculine style tend to show less of a concern for the face wants of others, and less focus on the relational aspect of interactions. Example (10) shows speaker PS3UM, who has been found to use a masculine style. This speaker is the chair of a highly structured agenda-driven meeting recorded in text file J9B:

Example (10). Masculine style in a highly structured agenda-driven meeting.

$\begin{array}{lll}\begin{array}{l}\text { PS3UM } \\ \text { J9BPSUNK }\end{array} & 251 & \begin{array}{l}\text { I'm sorry, yo-- yo-- you you're not listening to me. } \\ \text { PS3UM }\end{array} \\ \begin{array}{ll}253 & \text { I am listening to you. } \\ \text { The the the treasurer has already gone through the } \\ \text { report. }\end{array} \\ 254 & \begin{array}{l}\text { It is now up to members, to make observations, ask } \\ \text { questions, and then an amendment has been put, which is } \\ \text { er, accompanied to, direct negative over the recommen- } \\ \text { dations. }\end{array}\end{array}$

Example (10) shows speaker PS3UM producing an utterance that was coded as a confrontation. Immediately prior to this excerpt, interlocutor J9BPSUNK ${ }^{3}$ has been trying, rather persistently, to talk about a topic or an aspect of a topic that is not on the agenda; and in line 251, PS3UM accuses the other interlocutor of not listening. While the accusation is prefaced by an apology, the accusation itself is not hedged in any way. J9BPSUNK replies that $\mathrm{s} /$ he is listening. PS3UM ignores the response and produces an utterance $(253,254)$ that seems to be a report of the current situation, and which is spoken in a direct manner; there are no adverbs or comment clauses and no hedging of the suggestion that certain actions are 'up to members'. While Example (10) features a conflict, which partly explains the confrontational nature of the line 251 utterance, conflicts do not account for the referential style used by this speaker, or the lack of conciliatory strategies.

\subsection{Evidentiality use across styles}

The present section reports the results of the analysis of the evidentiality markers produced by the speakers listed in Table 3. During the analysis, the eviden- 
tial markers were found to fill seven functions of varying frequency; these are listed in Table 4 in order of the number of speakers who use them: ${ }^{4}$

Table 4: Functions of evidentiality markers and number of speakers who use them

\begin{tabular}{l|l|l}
\hline Function & Explanation & Users \\
\hline Face-saver & Modifying an utterance to make it less face threatening. & 7 \\
\hline Transparency & $\begin{array}{l}\text { Adding transparency regarding speaker's level or nature of } \\
\text { knowledge. }\end{array}$ & 7 \\
\hline Credibility & Increasing credibility of an assertion or argument. & 5 \\
\hline $\begin{array}{l}\text { Hedging assump- } \\
\text { tion }\end{array}$ & Hedging an assumption about another person's state of mind. & 5 \\
\hline Common ground & $\begin{array}{l}\text { Highlighting information that the speaker knows or assumes is } \\
\text { shared by the addressee(s). }\end{array}$ & 5 \\
\hline $\begin{array}{l}\text { Inviting assess- } \\
\text { ments }\end{array}$ & $\begin{array}{l}\text { Revealing limitations of evidence to invite additional assessments } \\
\text { of the relevant state of affairs. }\end{array}$ & 3 \\
\hline Distancing & $\begin{array}{l}\text { Distancing the speaker from an assertion by relieving the speaker } \\
\text { of some responsibility for the information. }\end{array}$ & 1 \\
\hline
\end{tabular}

As can be seen in Table 4, most of the evidentiality marker functions identified are used by more than half of the nine speakers; in other words, they are used across stylistic variation on the feminine-masculine scale. The four functions that are represented in all three stylistic types (feminine, masculine, and intermediate) to comparable degrees are illustrated and briefly explained below with Examples (11) through (14), from text files JP7, JNP, JA6, and JJA (in that order):

Example (11). Face-saver (by speaker of intermediate style).

PS4H6 709 In the media I mean I haven't seen much about it in the media. 710 Er

PS4H4 711 Well when when it was first read by erm < unclear $>$ it was mentioned that it had been written by the Green Party by radio four and the Guardian and the Independent.

712 And as far as I know that's the only coverage I've seen personally of it. 
Example (12). Transparency (by speaker of feminine style).

PS4FF 176 Can I take you back to the er the Good Report er about Trust Law, i-- it the report er concludes that it should be retained as the <unclear> framework for er occupation of pension schemes.

177 Now <pause dur="3"> I M P A C say that they believe there should be a dedicated pensions act to replace trust law and the National Federation Post Office and B T pensioners say trust law should continue to be the basis of pension funds.

Example (13). Credibility (by speaker of masculine style).

PS41A 137 But no, no, because we can make the assump--, we can make the assumption that it that the that they could get it, if they don't get it from us they'll get it from <gap desc="name" reason="anonymization" $>$ whatever the prices.

PS419 138 You see $<-\mid->$ at the moment $<-\mid->$

PS41A $139<-\mid->$ So we know that.

Example (14). Hedging assumption (by speaker of intermediate style).

PS44V 105 Erm if the Liberals wants <unclear $>$ they want to stop $<$ unclear> seventy two point six er million but they seem to do rather than go to seventy three point three which is what they want to reach, what they want $<$ unclear $>$ to look at originally.

Example (11) illustrates evidential marking as instrumental in maintaining another interlocutor's face. Speaker PS4H6 states that s/he has not seen much media coverage of their topic (709). Speaker PS4H4 responds by naming one radio station and two publications that have, in fact, mentioned the topic (711), then refers to her/his nature of access to evidence on the matter by adding that "as far as I know" this is the extent of the media coverage on that topic. This evidential marker hedges what would otherwise seem like a somewhat more direct correction of the statement made by speaker PS4H6. Example (12) is an illustration of evidential marking used to increase the transparency of an utterance. Speaker PS4FF marks hearsay evidentiality to specify where s/he acquired the 
information that Trust Law is the current framework for pension schemes, and that certain organizations hold opposing views on that topic. The utterance itself is a report used as a preface for a discussion; there is nothing to suggest a need for face maintenance or distance-taking. Rather, this speaker uses evidentiality to provide her/his addressees with additional transparency as $\mathrm{s} / \mathrm{he}$ introduces a new topic.

Contrarily to the case of Example (12), the utterance in focus in Example (13) is potentially face-threatening. As indicated by the initial "But no, no" (137), this utterance by speaker PS41A contradicts the preceding utterance by another speaker. Speaker PS41A proceeds to suggest that "we can make the assumption" that if they do not make a deal with a potential customer, that potential customer will be able to acquire what they need from someone else. Interrupting another speaker's attempt to respond, PS41A adds "so we know that", effectively upgrading her/his "assumption" to something s/he (and other interlocutors) knows, presumably from inference based on previous experience. Example (13) is interpreted as marking evidentiality to boost the credibility of an utterance by signalling that the speaker has access to highly reliable evidence.

In Example (14), speaker PS44V talks about how a political party other than the one s/he represents wants to settle for a lower sum of money (for something unspecified) than they were originally aiming for, modifying that statement with inferential evidential marker "seem to". Speakers were repeatedly found to highlight their evidential basis for assumptions regarding the intentions or state of mind of others; in some cases, this function overlaps with face-saving, and in others it overlaps with distancing, which is shown in Example (16).

Having thus presented the functions that appear to be used across styles, we now turn to what appear to be cases of co-variation. First, the three speakers who use evidential markers in the inviting assessments function are the three speakers found to use a feminine style; the speakers using a masculine or an intermediate style are not found to use that function. Example (15) shows speaker PS3S6 from text file J8B using an evidential marker in the inviting assessments function: 
Example (15). Feminine speaker using evidentiality to invite assessments

\begin{tabular}{|c|c|c|}
\hline PS3S6 & 1223 & $\begin{array}{l}\text { if you say in Playback }<-\mid->\text { there is an added night } \\
\text { performance }<-\mid->\end{array}$ \\
\hline PS3S2 & 1224 & $<-\mid->$ there will be a bus $<-\mid->$ \\
\hline PS3S6 & 1225 & you might get a phone call, if you say there's an \\
\hline J8BPSUNK & & $<$ unclear $>$ \\
\hline PS3S6 & 1226 & performance \\
\hline PS3S2 & 1227 & $\mathrm{Mm}$ \\
\hline PS3S6 & 1228 & $\begin{array}{l}\text { you know if you're in this area or that area we'll pick } \\
\text { you up and take you home }<-\mid->\text { and the phone just } \\
\text { doesn't stop ringing }<-\mid->\end{array}$ \\
\hline PS3S2 & 1229 & $<-\mid->$ Yeah, there's a bus going $<-\mid->$ \\
\hline PS3S4 & 1230 & $<-\mid->$ You got, yeah $<-\mid->$ \\
\hline PS3S5 & 1231 & Yes \\
\hline PS3S6 & 1232 & so I think there's a way of getting the blind people \\
\hline PS3S5 & 1233 & Yeah \\
\hline PS3S4 & 1234 & Yes I think there is \\
\hline
\end{tabular}

Text file J8B is a meeting on audio description - making theater performances accessible for blind people by providing audio descriptions of what is happening on stage - and the context of Example (15) is a discussion on additional strategies for motivating blind people to go to the theater. In lines 1223, 1225, 1226, and 1228, speaker PS3S6 says that if you say in Playback (which appears to be a magazine or paper) that there is an extra night performance there might be a phone call, but if you say that there is an extra performance and it is possible to get a ride home, there will be several phone calls. Then, in line 1232, speaker PS3S6 concludes that s/he thinks there is a way of motivating blind people to go to the theater. Think is an inferential evidential marker, signaling that the proposition "there's a way of getting the blind people" is based on an inference made by the speaker; the preceding utterances outline the basis of that inference. Simultaneously, the addition of "I think" to this proposition makes it appear more subjective and less definite; the speaker does not consider it an absolute truth. Suggesting that something is not the absolute, final truth invites confirmations, objections, or additions from the addressees; evidential markers used in 
the inviting assessments function tend to be used at points during a meeting when a solution or decision has to be arrived at and the speaker seeks consent from the other interlocutors. This interpretation of the evidential in Example (15) is reinforced by the expressions of agreement in lines 1233 and 1234; speaker PS3S4 even echoes the formulation used in line 1232. Out of the 20 occurrences evidential markers are used for inviting assessments, inferential evidentiality (think, which appears 14 times, and seem, presumably, gather) is marked in 18 occurrences; in the remaining two, hearsay markers (say, tell) are used; in other words, inferential markers are used 80 percent of the time. Out of the total of 122 evidential markers produced by the nine speakers, 31 ( 25 percent) are hearsay evidentials; that suggests inferential evidentiality is disproportionally common for the inviting assessments function (see appendix for evidentiality frequencies for the nine speakers).

Further, two functions that merit some analysis with regard to the possible co-variation of pragmatic functions of evidentiality markers with variation in gendered styles are distancing and common ground; these functions both appear most likely to occur with a masculine style. Distancing is used twice by speaker PS3UM from text file J9B, who is found to use a masculine style, and is shown in Example (16):

Example (16). Masculine speaker using evidentiality for distancing

J9BPSUNK 524 Yesterday, it was proposed that a committee be formed to look into speed limits.

525 The conservatives asked to be represented on that committee and they were refused by the ruling groups.

PS3UM 526 We were told that you might have as much effect on that as you're having with central government.

Example (16) begins with speaker J9BPSUNK stating that the forming of a committee has been proposed, and that the conservatives are being denied representation on that committee $(524,525)$. In utterances spoken prior to Example (16), it is implied that this speaker is a member of the conservative party, which suggests that the line 525 utterance is an implicit complaint. Speaker PS3UM's reply (526) implies a number of things. The $1^{\text {st }}$-person pronoun suggests that PS3UM is part of "the ruling groups" that decided the conservatives could not be represented, meaning that the complaint is partly directed at her/him; and the $2^{\text {nd }}$-person pronouns used in this utterance seem intended to be referring to the 
conservative party as a collective rather than speaker J9BPSUNK as an individual. The intended meaning of the entire utterance in line 526 appears to be that the effect the conservatives have with the central government is negative or insufficient, and that is the reason why they are not allowed on the committee. The effect of the evidential marker, we were told, is to distance the speaker from responsibility for the face-threatening assertion regarding the effect the conservatives would be likely to have, as the assessment was made by someone else.

The third function to be discussed here is common ground. This function could be seen as a variant of face-saving; it has the effect of attempting to involve the addressee(s), shielding them from a potentially face-threatening utterance by implying that the addressee is also an assessor rather than merely the recipients of the assessment. In most cases, common ground is performed using evidential marker obviously, as shown in Example (17) as used by masculine speaker PS4VB from text file JTD:

Example (17). Masculine speaker using evidentiality for common ground.

PS4VB $536 \quad$ I mean Mr Chairman it may just say honestly, I mean this is among ourselves from the commercial point of view there's no doubt about it, I'm in the grocery trade, the more you get on a lorry when you deliver $<-\mid->$ you get every single $<$ unclear $><-\mid->$

PS4VA $537<-\mid->$ Yes, well I mean, I think, I think it's fairly clear that we can appreciate.

PS4VB $538 \quad$ but er this is obviously the answer $<-\mid->$ for profit $<-\mid->$

PS4VA $539<-\mid->$ Yes, yes.

PS4VB 540 and I don't dispute that at all, but we're not here, I hope, making planning decisions

PS4VA $541 \quad$ Yes.

PS4VB 542 based upon a profit bottom line for Grant Development, we're here looking at the planning application and all the implications.

In Example (17), speaker PS4VB is voicing an objection to the general direction of the meeting discussion; and since speaker PS4VA is the chairperson, s/he becomes the target of PS4VB's objection. Speaker PS4VB says that $\mathrm{s} /$ he hopes they are not about to make planning decisions based on where the profit is (540, 
542), and uses evidential marker obviously while stating that the decision that the meeting is contemplating is one for profit (538). Here, speaker PS4VB is not only challenging the direction of the meeting discussion, which would have been face-threatening in itself, but s/he is directing the challenge at the chairperson, which makes this act even more marked. The evidential marker, along with the hedging expression "I don't dispute that at all" (540), softens the speaker's criticism by suggesting that the speaker and the addressee have common ground here; partly, s/he agrees with or at least understands the current direction of the discussion. Common ground is used by all three speakers found to use a masculine style. It is also used by feminine and intermediate speakers, but only by those with the highest word counts: PS6MC and PS4H4.

\section{Discussion and conclusion}

The research questions of this study were whether evidential marking is used for different functions depending on whether the communicational style is characterized by feminine or masculine behaviour, and whether any such co-variation reflects the previously found differences in evidentiality use between women and men. The method for identifying stylistic variation began with dividing the material into groups based on meeting type in order to control for variation in formality and the degree to which turn-taking was moderated by a chairperson. Then, the material was coded for features of gendered styles, as proposed by Holmes and Stubbe (2003), operationalized as lexical and pragmatic indicators. Further, the genders of the informants were masked by means of replacing names with anonymous combinations of letters and numbers, and by using transcripts only - not audio recordings - in order to prevent the analyst from becoming biased toward interpreting utterances a certain way because of the obvious gender of the speaker.

Judging by the results of the effort to rank informants from feminine to masculine according to their normalized frequencies of indicators of gendered styles, the method of coding for indicators was successful. The speakers who were ranked as the most masculine or the most feminine in their meeting groups do employ a style of interaction that is characterized by features previously recognized as part of a masculine or a feminine style, respectively. Of course, some sacrifices had to be made when the method was designed. For example, the decision to include indicators that are based on function rather than on form, such as justifier and people reference, has the drawback of making the coding process time-consuming, thus limiting the amount of data that could reasonably be used. Additionally, coding for function-based indicators inevitably brought a certain 
degree of subjectivity to the analysis, even though the material was analyzed twice to check for inconsistencies. However, it was deemed an insufficient measure for detecting variation in gendered styles to look only at frequencies of form-based categories. An additional factor that presented a methodological challenge for this study was the decision to ambiguate the genders of the speakers. It was integral to the aims of this paper to study variation across gendered styles, not genders, and for that reason it was decided to make a thorough effort to make the analysis about communication style regardless of speaker gender. As briefly discussed in Section 2.3, opting not to use audio files in the analysis in order to preserve the relative anonymity of the speakers presented an occasional limitation; yet, considering the previously mentioned potential of subjectivity being a factor in coding, it was deemed important to keep knowledge of the speakers' genders out of the analysis.

The evidentiality functions found in the present study (see Table 4) partly echo those found by Berglind Söderqvist (forthcoming), and the findings of evidentiality use across stylistic variation indicate some co-variation. The fact that the evidentiality function inviting assessments is used by the three speakers found to use a feminine interactional style, but not by the six speakers found to use an intermediate or masculine style, and the fact that inferential evidentiality markers are overrepresented with this function, suggest that having a certain interactional style might influence which evidential markers a speaker prefers, as well as how s/he uses them. Further, it seems that speakers using a masculine style are more likely to use evidentials in the common ground function, which features evidential adverb obviously in most cases. Inviting assessments tends to be used in the context of discussions of a supportive nature, where interlocutors appear intent on allowing everyone to be heard. It could be that a supportive style of interaction diminishes the occurrence of face-threatening situations such as the ones where common ground tends to be used.

The second research question concerns the potential correlation between variation in evidentiality use across gendered styles versus variation in evidentiality use between men and women. It should be noted, again, that the present study did not investigate variation between groups categorized according to speaker gender, but between groups classified according to certain stylistic choices - without considering the gender of the speaker making these stylistic choices. While gendered styles are, of course, related to the genders they are associated with, variations in evidential marking across gendered styles should not be assumed to directly reflect variations in evidential marking across female versus male speakers. This is partly why the present study was carried out: to investigate whether and to what extent these two different variation dimensions 
reflect one another - could it be that women use evidentials more frequently (Berglind Söderqvist 2017b) because evidentials constitute a common strategy in a feminine style? Berglind Söderqvist (2017a), who uses data drawn partly from the same category of BNC text files that were used for the present study, finds that among inferential evidentiality markers, women and men have different preferences. Women, Berglind Söderqvist (2017a) finds, are more likely than men to use think (among other markers), whereas one of the markers men are found more likely to use is obviously. In the present study, it was found that think is the marker most frequently used for evidentiality function inviting assessments, which appears most likely to occur in a feminine style, and that obviously is the marker most often used for evidential function common ground, which appears most likely to occur in a masculine style. This patterning suggests a possible correlation between gender-based preferences for evidential markers and variation in evidential marking across gendered styles. It is a correlation that would have to be tested further before it could be called evidence, however; for one thing, the nine speakers who were used for the qualitative evidentiality analysis in this study comprise precarious grounds for making generalizations.

To sum up, the findings of the present study hint at how a speaker's style influences evidentiality usage. They suggest that the kind of interactional style a speaker uses might promote differing ways of using evidentiality. The findings of this study do not out-rule the possibility of a correlation between variation in evidentiality functions across gendered styles and the previously found differences in evidentiality use between women and men; they even reinforce the notion that there could be such a correlation. However, the limited size of the material of this study also limits the representativeness of any conclusions that can be drawn. As for directions for future studies to bring clarity to the topic of the present paper, these findings suggest what previous studies have also hinted at: the pragmatic complexity of the inferential category of evidentiality markers. Further investigations to tease out the sociolinguistic and stylistic significance of evidential markers should, I would argue, be focused on inferential evidentiality.

\section{Notes}

1. From the British National Corpus; all examples are cited by their original text file designations and line numbers. Meta-textual information is designated by $<\ldots>$; overlapping speech is indicated by $<-\mid->$. 
2. For the sake of simplicity, the term gender is used throughout this article, even where other articles may have favored the term sex, to refer to individuals' acquired or assigned gender identities as well as gendered performances (cf. Butler 1990).

3. This speaker designation means that this speaker is unknown, i.e. did not give her/his name to the researcher when the recording was collected, or that the transcriber could not tell which of the speakers produced this utterance.

4. Due to limitations in the transcriptions, such as too many < unclear $>$ tags, 12 out of the 122 evidentiality markers produced by the nine speakers could not be conclusively categorized with regard to function and hence are excluded from Table 4.

\section{Primary source}

The British National Corpus, version 3 (BNC XML Edition). 2007. Distributed by Oxford University Computing Services on behalf of the BNC Consortium. URL: http://www.natcorp.ox.ac.uk/

\section{References}

Berglind Söderqvist, Erika. 2017a. Gender differences and similarities in the use of inferential evidentiality markers in spoken British English: A corpusbased study. In J. I. Marín-Arrese, J. Lavid-López, M. Carretero, E. D. Romero, M ${ }^{\mathrm{a}}$ V. M. de la Rosa and M. P. Blanco (eds.). Evidentiality and modality in European languages: Discourse-pragmatic perspectives (Linguistic Insights: Studies in Language and Communication 223), 371-399. Bern: Peter Lang.

Berglind Söderqvist, Erika. 2017b. Evidentiality across age and gender: A corpus-based study of variation in spoken British English. Research in Corpus Linguistics 5: 17-33.

Berglind Söderqvist, Erika. Forthcoming. Informational and relational functions of evidentiality in interaction. Studia Neophilologica.

Biber, Douglas. 2006. Stance in spoken and written university registers. Journal of English for Academic Purposes 5: 97-116.

Butler, Judith. 1990. Gender trouble: Feminism and the subversion of identity. New York and London: Routledge. 
Cappelli, Gloria. 2007. 'I reckon I know how Leonardo da Vinci must have felt': Epistemicity, evidentiality and English verbs of cognitive attitude. Pari: Pari Publishing.

Carretero, Marta and Juan Rafael Zamorano-Mansilla. 2013. An analysis of disagreement-provoking factors in the analysis of epistemic modality and evidentiality: The case of English adverbials. Proceedings of the IWCS 2013 Workshop on Annotation of Modal Meanings in Natural Language (WAMM), 16-23.

Cornillie, Bert. 2009. Evidentiality and epistemic modality: On the close relationship between two different categories. Functions of Language 16 (1): 44-62.

Drew, Paul. 2018. Epistemics in social interaction. Discourse Studies 20 (1): 163-187.

Fox, Barbara A. 2001. Evidentiality: Authority, responsibility, and entitlement in English conversation. Journal of Linguistic Anthropology 11 (2): 167192.

Holmes, Janet. 2008. Gendered Discourse at Work. Language and Linguistics Compass 2 (3): 478-495.

Holmes, Janet and Meredith Marra. 2004. Relational practice in the workplace: Women's talk or gendered discourse? Language in Society 33 (3): 377-398.

Holmes, Janet and Stephanie Schnurr. 2006. Doing femininity' at work: More than just relational practice. Journal of Sociolinguistics 10 (1): 31-51.

Holmes, Janet and Maria Stubbe. 1997. Good listeners: Gender differences in New Zealand conversation. Women and Language 20 (2): 7-14.

Holmes, Janet and Maria Stubbe. 2003. Feminine' workplaces: Stereotype and reality. In J. Holmes and M. Meyerhoff (eds.). The handbook of language and gender, 573-599. Oxford: Blackwell.

Ladegaard, Hans J. 2011. Doing power' at work: Responding to male and female management styles in a global business corporation. Journal of Pragmatics 43: 4-19.

McDowell, Joanne. 2015. "Masculinity and non-traditional occupations: Men's talk in women's work. Gender, work and organisation 22 (3): 273-291.

Merrill, Natalie, Emily Gallo and Robyn Fivush. 2015. Gender differences in family dinnertime conversations. Discourse Processes 52 (7): 533-558.

Mulac, Anthony, John M. Wiemann, Sally J. Widenmann and Toni W. Gibson. 1988. Male/female language differences and effects in same-sex and mixed- 
sex dyads: The gender-linked language effect. Communication Monographs 55: 315-335.

Newman, Matthew L., Carla J. Groom, Lori D. Handelman and James W. Pennebaker. 2008. Gender differences in language use: An analysis of 14,000 text samples. Discourse Processes 45: 211-236.

Willett, Thomas. 1988. A cross-linguistic survey of the grammaticization of evidentiality. Studies in Language 12 (1): 51-97.

\section{Appendix}

Table 1A: Normalized (and raw) evidentiality frequencies of the 9 speakers

\begin{tabular}{l|l|l|l|l|l}
\hline Speaker & Style & Word count & Hearsay & Inferential & Sensory \\
\hline PS6MC & F & 7,026 & $1.42(10)$ & $4.41(31)$ & 0 \\
PS3S6 & F & 3,490 & $0.86(3)$ & $2.58(9)$ & 0 \\
PS4FF & F & 1,875 & $1.07(2)$ & $1.07(2)$ & 0 \\
\hline PS4H4 & I & 5,858 & $2.22(13)$ & $4.95(29)$ & $0.17(1)$ \\
PS1LN & I & 1,245 & 0 & $0.8(1)$ & 0 \\
PS44V & I & 1,649 & $0.61(1)$ & $1.81(3)$ & 0 \\
\hline PS4VB & M & 1,007 & 0 & $3.97(4)$ & 0 \\
PS41A & M & 2,238 & 0 & $2.23(5)$ & 0 \\
PS3UM & M & 1,441 & $0.69(1)$ & $4.86(7)$ & 0 \\
\hline
\end{tabular}

